\title{
WEB, WEB SEMÂNTICA E WEB PRAGMÁTICA: um posicionamento da Arquitetura da Informação
}

\author{
WEB, SEMANTIC WEB AND PRAGMATIC WEB: \\ position of Information Architecture
}

\author{
Silvana Aparecida Borsetti Gregorio Vidotti \\ Caio Saraiva Coneglian ${ }^{2}$ \\ Sandra Milena Roa-Martínez ${ }^{3}$ \\ Fernando Luiz Vechiato ${ }^{4}$ \\ José Eduardo Santarém Segundo ${ }^{5}$
}

\begin{abstract}
RESUMO
A expansão no uso de ambientes informacionais digitais, em especial da Web, trouxe a necessidades de aprimorar a interacão entre os indivíduos e os mecanismos computacionais. Neste sentido, a Web possibilita a publicação de conteúdos, a Web Semântica busca inserir significado aos conteúdos disponíveis na Web, enquanto a Web Pragmática busca inserir contexto aos conteúdos. A Arquitetura da Informacão busca fornecer subsídios teóricos e aplicados para a criacão de ambientes digitais, com foco ao atendimento das necessidades informacionais dos usuários, considerando ainda, o contexto e o conteúdo. Assim, questiona-se como as teorias e os campos relacionados à Arquitetura da Informação, estudados pela Ciência da Informação, se relacionam com a Web, a Web Semântica e a Web Pragmática. Diante disso, objetivou-se identificar e explorar a relação existente entre a Arquitetura da Informacão, a Web, a Web Semântica e a Web Pragmática. Para tal, utilizou-se uma metodologia qualitativa, de caráter bibliográfico e analítico. Enquanto resultados, identificou-se que a Arquitetura da Informação, tendo como prisma a sua teoria sistêmica, é aprimorada quando faz uso da Web Semântica, enquanto que a Arquitetura da Informação, em conjunto com os campos de estudos que utilizam de seu arcabouço teórico, quais sejam, a Encontrabilidade da Informaç̧ão, a Usabilidade, a Pervasividade e a Experiência de Usuário, promove a materialização da Web Pragmática. Concluiu-se assim, que a relação existente ocorre quando a Arquitetura da Informação enriquecida com seus campos de estudos incorpora as tecnologias da Web Semântica e, passa a ser uma propiciadora da Web Pragmática.
\end{abstract}

Palavras-chave: Arquitetura da Informação. Web. Web Semântica. Web Pragmática. Contextos pragmáticos.

\begin{abstract}
The expansion in the use of digital information environments, especially the Web, has brought to the need of improving the interaction between individuals and computational mechanisms. In this regard, the Web makes it possible to publish content, the Semantic Web seek to insert meaning to the contents available in the Web, while the Web Pragmatic look to add the context of these contents. Information Architecture seeks to provide theoretical and applied subsidies for the digital environments creation that can meet the user's information needs, considering also the context and content. In this way, it is questioned how the theories and fields related to Information Architecture, studied by Information Science, are related to the Web, Semantic Web and Pragmatic Web. Thus, this paper aims to identify and explore the relationship between Information Architecture, Web, Semantic Web and Pragmatic Web. For this, a qualitative methodology was used, with a bibliographic and analytical character. As results, it was identified that the Information Architecture, having as its prism its systemic theory, is improved when it makes use of Semantic Web, while Information Architecture with of the fields of studies that use of its theoretical framework, such as Information Findability, Usability, Pervasiveness and User Experience, promoting the materialization of the Pragmatic Web. It was concluded that the existing relationship occurs when the Information Architecture enriched with its fields of study incorporates the technologies of the Semantic Web and, it becomes a facilitator of the Web Pragmatic.
\end{abstract}

Keywords: Information Architecture. Web. Semantic Web. Pragmatic Web. Pragmatic contexts.

Artigo recebido em 11/02/2018 e aceito para publicação em 12/03/2019

1 Doutora em Educacão pela Universidade Estadual Julio de Mesquita Filho, Brasil. Docente permanente no Programa de Pós-Graduação em Ciência da Informação da Universidade Estadual Julio de Mesquita Filho, Brasil. Bolsista de Produtividade do CNPq. E-mail: silvana.vidotti@unesp.br.

2 Mestre em Ciência da Informação pela Universidade Estadual Julio de Mesquita Filho, Brasil.. Bacharel em Ciência da Computação pelo Centro Universitário Eurípedes de Marília, Brasil. Doutorando no Programa de Pós-Graduação em Ciência da Informação da Universidade Estadual Julio de Mesquita Filho, Brasil. E-mail: caio.coneglian@gmail.com.

3 Mestre em Ingeniería Electrónica pela Universidad Del Valle, Colômbia. Professora Titular da Universidad Del Cauca, Colômbia. Doutoranda no Programa de Pós-Graduação em Ciência da Informação da Universidade Estadual Julio de Mesquita Filho, Brasil. E-mail:smroa@unicauca.edu.co.

4 Doutor em Ciência da Informação pela Universidade Estadual Julio de Mesquita Filho, Brasil. Professor Adjunto do Departamento de Ciência da Informaç̃o da Universidade Federal do Rio Grande do Norte, Brasil. Docente colaborador do Programa de Pós-Graduacão em Ciência da Informacão da Universidade Estadual Paulista Julio de Mesquita Filho, Brasil. E-mail: vechiato2008@gmail.com.

5 Doutor em Ciência da Informação pela Universidade Estadual Paulista Júlio de Mesquita Filho, Brasil. Professor no Departamento de Educação, Informação e Comunicação, da Faculdade de Filosofia, Ciências e Letras de Ribeirão Preto da Universidade de São Paulo, Brasil. Docente permanente no Programa de Pós-Graduação em Ciência da Informaç̧ão da Universidade Estadual Julio de Mesquita Filho, Brasil. E-mail: santarem@usp.br. 


\section{INTRODUÇÃO}

0 uso de ambientes informacionais digitais é parte do cotidiano dos indivíduos, em que em especial a World Wide Web (Web) passou a ser a plataforma para realizar atividades como compras, entretenimento e emissão de notas fiscais. Atualmente, conceber a nossa interação com a sociedade, com o governo e com as organizações sem perpassar em algum momento pelo ciberespaço é utópico.

Neste contexto, a Web que foi desenvolvida em 1989, foi evoluindo, buscando se aprimorar para atender com eficiência aos indivíduos proporcionalmente ao grau de importância que ela passou a ter para a sociedade. 0 desenvolvimento da Web Semântica, que em suma, buscava inserir significado aos conteúdos contidos na Web, foi uma das primeiras iniciativas com este fim, sendo bem-sucedida no desenvolvimento de tecnologias que aproximaram a comunicação das pessoas com a dos agentes computacionais.

Uma outra iniciativa que visa aprimorar a Web, porém que ainda não atingiu o grau de maturidade da Web Semântica, é a Web Pragmática. A Web Pragmática tem como ideal ir além da significação do conteúdo, buscando interagir e compreender o contexto que os conteúdos e que os indivíduos possuem na utilização dos ambientes informacionais digitais da Web.

Complementarmente, a Arquitetura da Informação, como disciplina, busca fornecer subsídios teóricos e aplicados para a criação de ambientes digitais, que consigam atender de forma eficiente as necessidades de informação dos usuários. Neste contexto, a Arquitetura da Informação vem evoluindo, trazendo campos de estudos que utilizam de seu bojo teórico para aprimorar a forma como os usuários interagem com os ambientes informacionais.

A inter-relação entre a Web e a Arquitetura da Informação é essencial para tornar os ambientes da Web mais efetivos, os quais utilizam as evoluções que as tecnologias da Web Semântica trouxeram e os conceitos que a Web Pragmática propõe. No entanto, é necessário delinear como e de qual forma as teorias e os campos relacionados a Arquitetura da Informação se relacionam com a Web Semântica e com a Web Pragmática.

Desta forma, o objetivo deste trabalho é de identificar e explorar a relação existente entre a Arquitetura da Informação, a Web Semântica e a Web Pragmática, considerando a tríade usuário, conteúdo e contexto. Para tal, utilizou-se de uma metodologia qualitativa, de caráter bibliográfico, em que se buscou subsídios teóricos sobre Web Semântica, Web Pragmática e Arquitetura da Informação, tendo também caráter analítico, onde a partir dos pressupostos encontrados, traçou-se a relação entre a Arquitetura da Informação, a Web Semântica e a Web Pragmática. 


\section{WEB, WEB SEMÂNTICA E WEB PRAGMÁTICA}

A Web foi concebida inicialmente em 1989, por Tim Berners-Lee, buscando criar um meio de troca de dados utilizando a infraestrutura da Internet, tendo como base o conceito do hipertexto. A partir da sua criação, a Web se popularizou e passou em poucos anos a estar presente no cotidiano das pessoas, em que em grande parte das atividades desenvolvidas por um indivíduo, a Web se encontra atuante.

Diante deste cenário, a inserção dos indivíduos no chamado ciberespaço, passou a ser algo natural, em que as pessoas se adentraram de forma permanente e constante neste ambiente virtual. Neste contexto, Monteiro (2006, p. 32-33) aponta que o ciberespaço é:

[...] 0 espaço possível de criação de expressões culturais, ou seja, a cibercultura, de transações comerciais, econômicas e sociais [...] 0 ciberespaço parece encarnar a força virtual, em curso de atualização, mas, ao mesmo tempo, sem perder a sua virtualidade, pois o virtual como realidade diz respeito ao modo de ser das "coisas" incorpóreas, portanto da ordem da memória e da produção simbólica [...]

Diante da explanação da autora, verifica-se que o ciberespaço se torna um elemento que perpassa as diversas atividades das organizações e dos indivíduos, tendo uma relação direta com a virtualidade, o que aprofunda e torna complexo os processos inerentes aos ambientes como a Web.

Tendo como foco tal complexidade, é necessário compreender o desenvolvimento da Web posteriormente a sua concepção. Neste sentido, nos seus primeiros anos, a Web se tornou um ambiente com um volume de dados muito elevado, sem ter uma descrição ou um controle sobre as informações ali contidas. Em um texto publicado em 2004, Souza e Alvarenga (2004, p. 133) refletem e discorrem acerca da situação da Web neste contexto:

Embora tenha sido projetada para possibilitar o fácil acesso, intercâmbio e a recuperação de informações, a Web foi implementada de forma descentralizada e quase anárquica; cresceu de maneira exponencial e caótica e se apresenta hoje como um imenso repositório de documentos que deixa muito a desejar quando precisamos recuperar aquilo de que temos necessidade.

As questões apresentadas pelos autores apontam a dificuldade de recuperar e de encontrar as informações quando necessário. Neste sentido, a falta de descritores e de metadados para auxiliar agentes computacionais e mecanismos de buscas, tornavam os documentos contidos na Web majoritariamente preparados unicamente para a leitura humana, sem ter tecnologias que possibilitassem a compreensão do conteúdo por mecanismos computacionais.

Diante deste cenário e tendo em vista a dimensão e a importância que a Web passou a ter na forma como o mundo se constitui, era necessário que este ambiente fosse revisto e que se buscasse meios 
de tornar a comunicação entre pessoas e mecanismos computacionais mais próxima. Assim, a Web Semântica foi proposta por Berners-Lee, Hendler e Lassila (2001) visando solucionar a problemática descrita e ser uma evolução da Web inicial. Os autores afirmam ainda que: "A Web Semântica não é uma Web separada, mas uma extensão da atual, na qual a informação tem um significado bem definido, permitindo que os computadores e as pessoas trabalhem em cooperação." (BERNERS-LEE; HENDLER; LASSILA, 2001, não paginado, tradução nossa).

Partindo desse ideal de possibilitar a integração e cooperação de pessoas e computadores, a Web Semântica foi concebida buscando desenvolver tecnologias capazes de transmitir o significado que um conteúdo possui para um agente computacional. Tal fato está embasado principalmente na busca de descrever os conteúdos dos dados em uma semântica formal, que fosse compreensível para as máquinas. Como consequência dessa compreensão, seria possível construir aplicações que realizassem inferências sobre os dados tratados e permitisse uma forma do usuário recuperar informações com mais facilidade e navegasse em um ambiente mais organizado.

Passados mais de quinze anos da proposta da Web Semântica, verifica-se que uma gama de tecnologias foi desenvolvida visando tornar real e implementável a proposta inicial. Santarém Segundo e Coneglian (2016, p. 218) discorrem acerca das principais tecnologias que tangenciam a Web Semântica:

[...] 0 uso dos principais padrões de metadados para descrição de objetos digitais, a linguagem eXtensible Markup Language (XML) e sua facilidade para interoperar dados, a linguagem Resource Description Framework (RDF) e sua capacidade de conectar recursos, as ontologias e suas linguagens de construção, como Web Ontology Language (OWL), que possibilita contextualizar e tornar computável a conceitualização de domínios e processos, o Protocol and RDF Query Language (SPARQL), capaz de interagir diretamente com os dados e tornar possível a recuperação da informação nesse contexto [...].

As tecnologias descritas pelos autores auxiliam na realização desde os processos de descrição e organização dos dados (RDF), passando pela recuperação dos dados (SPARQL), chegando até a linguagens para a construção de ontologias (OWL). No que concerne especificamente a ontologias, destaca-se que este artefato é um elemento fundamental para tornar possível a Web Semântica, pois são elas as responsáveis por descrever um domínio formalmente, apontando as relações existentes e propriedades que permitem a descrição da semântica formal contida nos dados.

Ainda que as ontologias, enquanto artefatos pertencentes ao escopo da Web Semântica, sejam capazes de aprimorar a forma como os computadores compreendem um determinado domínio, 0 processo de contextualização dos dados ainda não é consenso como algo que a Web Semântica e as 
suas tecnologias sejam capazes de promover. Neste âmbito, seria função da Web Pragmática, uma evolução da Web Semântica, criar tecnologia capazes de contextualizar os dados.

Moor, Keeler e Richmond (2002) ao apresentar a Web Pragmática aponta que a Web Semântica é necessária para criar uma estrutura em que o significado dos dados seja bem definido, porém é incapaz de atender as necessidades das comunidades virtuais atuais. Os autores apontam desta forma que a Web Pragmática permite a definição e a automatização dos processos pragmáticos dentro da Web, de modo que os sistemas humanos e tecnológicos estejam calibrados conjuntamente. Mota e Kobashi (2016, p. 2) complementam esta visão, afirmando que: "[...] a Web Pragmática como um conjunto de tecnologias para criar representações de contextos na Web, de forma a aprimorar os processos de recuperação da informação."

Diante do exposto, verifica-se que a Web Pragmática está focada em possibilitar que o contexto dos dados e do indivíduo sejam elementos considerados para a recuperação da informação e do próprio uso que este indivíduo tem ao navegar na Web. Tal conceito diferencia da Web Semântica, por ir além de dar significado aos dados, pretendendo dar o contexto ao qual eles pertencem.

Uma discussão sobre Web Sintática, Web Semântica e Web Pragmática está relacionada com os termos sintaxe, semântica e pragmática, que possuem significados distintos. Mota (2015) relata que a sintaxe é a combinação de palavras, frases e sentenças, a semântica é o significado das palavras, frases e sentenças e, a pragmática é o significado contextual das palavras, frases e sentenças.

Decarli (2017) complementa esta relação apontando que a pragmática advém do pragmatismo (corrente em que a validade de uma doutrina está relacionada ao sucesso de sua prática), na relação entre os signos e os seus intérpretes. 0 autor ainda traz a afirmação de Pinto (2006, p. 47 apud DECARLI, 2017, p. 53), em que a sintaxe e a semântica se diferenciam da pragmática, pois esta última busca: "[...] o uso concreto da linguagem, com vistas em seus usuários [...] na prática linguística [...]" Diante destas questões, verifica-se que a Web Pragmática tem o seu princípio na possibilidade do computador interagir de modo mais assertivo e eficiente com o usuário, uma vez que será capaz de compreender o contexto do usuário e assim entregar a este indivíduo as informações que respondem a suas necessidades com mais precisão.

A Web Pragmática pode ser compreendida então como:

[...] pautada no conhecimento consensual da comunidade sobre um mesmo objeto. Assim, contempla não apenas o significado, mas também a maneira como ele é empregado por diferentes grupos. Dessa maneira, faz a junção entre a lógica dos dados estruturados, a comunidade Web, o significado consensual e múltiplos contextos. (DECARLI, 2017, p. 55) 
A definição apresentada contempla os aspectos linguísticos que embasam o termo Web Pragmática, ao mesmo tempo que permite visualizar a relação principal desta Web em permitir que as tecnologias sejam capazes de entregar aos indivíduos informações contextualizadas, com conhecimento consensual e explícito.

Além disso, para Moor (2005) a Web Semântica pode ser entendida como uma coleção de recursos semânticos sobre a Web sintática (por exemplo, por meio das ontologias que contêm redes semânticas de conceitos, relações e regras que definem o significado dos recursos informacionais) e a Web Pragmática como um conjunto de contextos pragmáticos de recursos semânticos. Vale destacar que para o autor supracitado um contexto pragmático se compõe de:

[...] um contexto comum e um conjunto de contextos individuais. Um contexto comum é definido pelos conceitos comuns e definições conceituais de interesse para uma comunidade, as interações comunicativas em que esses conceitos são definidos e usados e um conjunto de parâmetros de contexto comuns (propriedades relevantes de conceitos, metas comuns, situação comunicativa e em breve). Cada membro da comunidade também possui um contexto individual, consistindo em conceitos individuais e definições de interesse e parâmetros de contexto individuais. (M00R, 2005, p. 6, tradução própria)

Neste cenário, é possível destacar que a Web Pragmática é uma evolução da Web Semântica, e das próprias tecnologias da Web Semântica, uma vez que, com a evolução destes ferramentais, aplicações utilizando o contexto dos dados começam a tornar-se necessárias de ser implementadas.

Também, se observa que ao passar da Web (Sintática) para a Web Semântica há uma diminuição no número de elementos, que aumenta novamente ao passar da Semântica para a Web Pragmática. Ou seja, há um alto volume de recursos de informação (sintáticos) para um domínio específico, então haverá menos ontologias que definam os significados desses recursos. No entanto, poderão ser gerados infinitos contextos pragmáticos, dado que existem múltiplas dimensões da pragmática a serem consideradas, o que leva a uma grande variedade de contextos. Para Moor (2005, p. 6), " [...] os múltiplos contextos pragmáticos são ainda mais difíceis de formalizar e padronizar do que a semântica dos conceitos que interpretam. As visualizações do contexto individual podem concordar entre si ou diferir.".

Ainda que a totalidade da Web esteja inserida no âmbito da Web Pragmática, a evolução das tecnologias da Web Semântica e o aprimoramento constante dos mecanismos de buscas passam a ser elementos indicadores que a Web Pragmática se aproxima, e deve promover ambientes mais inteligentes e integrados às necessidades informacionais dos usuários. Assim, destaca-se que o próprio uso e aprimoramento da Inteligência Artificial pode promover a materialização da Web Pragmática, em um 
processo que deve abranger as ontologias como elementos que podem contribuir na integração e na compreensão de um cenário por agentes inteligentes que teriam a função de aproximar os indivíduos e os computadores.

As discussões tratando da Web e de como os indivíduos a utilizam estão fortemente vinculadas à Arquitetura da Informação Digital. Especialmente no que tange a Web Pragmática e essa aproximação no contexto dos usuários e dos dados, a Arquitetura da Informação torna-se peça chave para propiciar uma integração real entre computador e máquina, ao enfocar-se nas questões relativas ao modo como as informações irão interagir com os indivíduos, e vice-versa. Desta forma, na próxima seção apresentase os conceitos inerentes à Arquitetura da Informação, tanto de sua teoria sistêmica, quanto de suas novas abordagens epistemológicas.

\section{ARQUITETURA DA INFORMAÇÃO AMPLIADA}

0 termo Arquitetura da Informação foi disseminado por Richard Wurman na década de 1960, refletindo uma necessidade deste arquiteto que se interessou por reunir, organizar e apresentar as informações da melhor forma possível para um público diverso. Posteriormente, no ano de 1976, os estudos de Arquitetura da Informação começaram a se consolidar com a conferência do American Institute of Architects (AIA). (DIAS; VID0TTI, 2012).

Com a evolução das Tecnologias da Informação e Comunicação e da própria criação e massificação da Web, os estudos de Arquitetura da Informação passaram a ser aplicados em ambientes informacionais digitais. Os estudos e os projetos de Arquitetura da Informação Digital, como foi denominada a Arquitetura da Informação nesses ambientes, logo se tornaram fundamental durante a construção de ambientes informacionais digitais e de websites, pois era necessário ter uma reflexão maior acerca do modo como as informações seriam organizadas e apresentadas nestes ambientes.

Wyllys (2000) demonstra claramente esse período, ao descrever que o arquiteto da informação nesse momento tinha uma conotação de atuação muito vinculada a organização da informação na Web. 0 autor ainda complementa que este cenário, especialmente vinculado aos profissionais da biblioteconomia e da Ciência da Informação pode ter sido causado por: "[...] ser parte das oportunidades surgidas durante a década de 1990 para repensar a apresentação do catálogo da biblioteca, pois essas informações de acesso público on-line (OPAC) e [...] [pela] proliferação de informações sobre a Web." (WYLLYS, 2000, tradução nossa). 
Atualmente, a Arquitetura da Informação vem sendo discutida e aplicada em diversos ambientes digitais, buscando tornar mais eficiente a utilização destes ambientes pelos usuários. Neste contexto, os arquitetos da informação criam projetos para sistemas Web, aplicativos para dispositivos móveis, aplicações de realidade aumentada e virtual, entre diversas outras aplicações digitais existentes.

No âmbito da Ciência da Informação, o conceito de Arquitetura da Informação vem sendo trabalhado há alguns anos, e tem um marco inicial com a publicação do livro Information Architecture for the World Wide Web de Roselfend e Morville (1998). Neste livro, os autores trazem de forma prática, como deve ocorrer o projeto de Arquitetura da Informação, trazendo para o centro do debate 0 profissional da Informação.

Em uma edição mais recente deste livro, os autores Rosenfeld, Morville e Arango (2015, p. 24, tradução nossa), trazem quatro definições para o termo Arquitetura da Informação:

1. 0 projeto estrutural de ambientes de informações compartilhadas; 2. A associação de organização, de rotulagem, de busca e de navegação sistemas dentro de canais de digitais e físicos; 3. A arte e a ciência de moldar produtos de informação e experiências para apoiar a usabilidade, encontrabilidade, e 0 entendimento; 4. Uma disciplina emergente e comunidade de prática focada em trazendo princípios de design e arquitetura para os ambientes digitais.

As definições apresentadas perpassam pelas questões referentes ao projeto de ambientes de informação, até pela concepção teórica do termo Arquitetura da Informação. Neste contexto, é possível visualizar a amplitude que o termo possui, sendo inclusive uma disciplina que busca contribuir no desenvolvimento de ambientes digitais.

Ainda neste livro, os autores conceituam a clássica teoria sistêmica da Arquitetura da Informação, que a divide em quatro sistemas: Organização; Rotulagem; Busca; e Navegação. Os autores ainda citam outros instrumentos como vocabulários controlados, tesauros, metadados e ontologias, que foram consideradas por Oliveira e Vidotti (2012) como um novo sistema, o sistema de Representação.

0 sistema de organização está focado na estruturação dos conteúdos de uma forma que os usuários consigam compreender o modo como 0 ambiente digital está organizado. Em suma, as estruturas utilizadas devem ser representativas e significativas para os indivíduos, utilizando esquemas claros e coerentes com 0 ambiente em questão.

O segundo tipo de sistema existente na Arquitetura da Informação, são os sistemas de rotulagem. A rotulagem tem a função de descrever determinadas informações ou conjuntos de informações, de forma que o usuário entenda facilmente o conteúdo ali descrito, ou o conteúdo obtido caso acesse algum link determinado. 
Já os sistemas de navegação buscam permitir com que um usuário se localize facilmente em um ambiente informacional digital, e possa assim, encontrar mais naturalmente as informações desejadas. Este sistema deve permitir com que o usuário tenha diversos modos e caminhos para localizar uma informação no ambiente.

0 sistema de busca é um outro mecanismo para que o usuário encontre as informações desejadas, sendo complementar aos sistemas de navegação. Neste sistema, além de promover mecanismos de buscas que recuperem resultados satisfatórios a necessidades dos usuários, é necessário refletir e oferecer interfaces que forneçam as informações necessárias para o usuário entender as possibilidades e modos de uso fornecidos a ele.

Por fim, 0 último sistema da Arquitetura da Informação é o sistema de representação. Esse tipo de sistema tem a função de auxiliar nos processos de recuperação da informação, organização, navegação, busca e outras atividades executadas dentro de um ambiente digital, ao fornecer estruturas como metadados, tesauros, vocabulários controlados e ontologias.

Os sistemas da Arquitetura da Informação apresentados fornecem um panorama claro dos elementos que devem constar e ser considerados em um projeto de Arquitetura da Informação. Neste contexto, vale destacar o caráter aplicado e prático que esta sistematização possui, uma vez que os autores Rosenfeld, Morville e Arango (2015) ao definir os sistemas, apresentam com detalhes a forma como cada um dos sistemas devem ser analisados e construídos ao criar um projeto de Arquitetura da Informação.

Com a consolidação da Arquitetura da Informação na área da Ciência da Informação, tendo como ponto de partida os sistemas de Rosenfeld, Morville e Arango (2015), foi possível aprofundar em discussões epistemológicas que se relacionam a Arquitetura da Informação, o que permitiu a criação de novos campos de estudos que estão intrinsecamente vinculados a esta disciplina, e que neste trabalho foi denominado Arquitetura da Informação Ampliada.

Dentre esses campos, vale destacar a Arquitetura da Informação Pervasiva, a Encontrabilidade da Informação, a Usabilidade e a Experiência do Usuário. Tais campos ou nasceram tendo algum vínculo com a Arquitetura da Informação, ou passou a fazer parte de estudos que relacionam e utilizam pressupostos teóricos comuns.

A Arquitetura da Informação Pervasiva foi discutida inicialmente por Resmini e Rossati (2011) apresentando uma nova visão da Arquitetura da Informação que extrapola os ambientes informacionais digitais, passando a considerar os diversos espaços e ecologias que um usuário se encontra e interage, 
que estão consequentemente, relacionado aos ambientes digitais, mas não limitado a eles. Oliveira (2013, p. 166) conceitualiza a Arquitetura da Informação Pervasiva como:

[...] uma abordagem teórico-prática da disciplina científica pós-moderna Arquitetura da Informação, trata da pesquisa científica e do projeto de ecologias informacionais complexas. Busca manter o senso de localização do usuário na ecologia e o uso de espaços, ambientes e tecnologias de forma convergente e consistente. Promove a adaptação da ecologia à usuários e aos novos contextos, sugerindo conexões no interior da ecologia e com outras ecologias.

A partir da definição do autor, verifica-se a relação da informação, com as ecologias informacionais complexas, extrapolando os ambientes digitais, e considerando os contextos pragmáticos existentes nestas ecologias. Neste âmbito, a informação passa a estar e fluir nas diversas telas e dispositivos existentes, que em tempos de Internet das Coisas, onde grande parte dos objetos podem estar conectados na rede de computadores, a Arquitetura da Informação não se limita a pensar e projetar sistemas Web e websites, tendo que refletir e auxiliar em projetos dessas ecologias.

Outro campo de estudo relacionado a Arquitetura da Informação Pervasiva é a Encontrabilidade da Informação. Este termo foi apresentado por Vechiato e Vidotti (2014, p. 164), afirmando que a Encontrabilidade da Informação: “[...] sustenta-se fundamentalmente na interseção entre as funcionalidades de um ambiente informacional e as características dos sujeitos informacionais".

A Encontrabilidade da Informação está centrada em como o usuário pode encontrar uma informação, identificando atributos e elementos que facilitam e promovem as atividades dos usuários ao utilizar um determinado ambiente digital. Morville (2005) aponta ainda que a encontrabilidade está relacionado a questões de como um objeto pode ser facilmente descoberto, além de considerar a qualidade como este processo ocorre, estando relacionado a recuperação e a navegação dos ambientes. Assim, se evidencia a necessidade da identificação dos contextos individuais e do contexto comum que se constituem no contexto pragmático da Encontrabilidade da Informação.

Em outra perspectiva, os estudos de Usabilidade vêm sendo feitos a vários anos, buscando identificar o quão usável um ambiente pode ser. Há diversas formas de avaliar usabilidade, como as heurísticas de Nielsen (1995) que apresentam regras gerais, com foco na interface, em que especialistas devem realizar a avaliação. A usabilidade vem auxiliando os projetos de Arquitetura da Informação, uma vez que fornece elementos para aprimorar esses projetos ao permitir uma avaliação quantificável e capaz de analisar se 0 ambiente favorece 0 seu uso. 
Por fim, a Experiência de Usuário além de contemplar as questões de usabilidade foca seus esforços na satisfação que o usuário tem ao utilizar um ambiente informacional, buscando identificar e analisar as sensações causadas durante a interação entre estes.

No ambiente digital, Carraro e Duarte (2015) apontam que a Experiência de Usuário acontece no ato de comunicação do usuário e da máquina por meio de uma interface, sendo que, tal interface pode ser um website, um dispositivo móvel ou um software.

A experiência de usuário é o campo que, por meio de disciplinas como a Arquitetura da Informação, o desenho de interação e a usabilidade, estuda as emoções, pensamentos e sensações que as pessoas experimentam quando usam um produto com o objetivo de desenhar experiências prazerosas. (CARRAR0; DUARTE, 2015, não paginado, tradução própria).

Assim, além da relação com a Arquitetura da Informação, estudar a Experiência de Usuário de um ambiente informacional digital, permite promover experiências de maior qualidade, influenciando de forma concreta sobre como será a aceitação deste para um usuário. Ou seja, há de ser considerado o contexto pragmático construído a partir dos contextos individuais dos usuários buscando aprimorar a Experiência do Usuário no contexto comum do ambiente informacional digital.

Diante da explanação dos sistemas da Arquitetura da Informação e de alguns campos de estudos que estão relacionados epistemologicamente com esta disciplina, a seguir apresenta-se os resultados e as discussões deste trabalho, em que são relacionados tais teorias com a Web Semântica e a Web Pragmática.

\section{RESULTADOS E DISCUSSÕES}

A Web e a Arquitetura da Informação estão intrinsecamente relacionadas, em especial pelos estudos que buscam construir projetos de websites considerando e refletindo acerca de como tornar o uso dos ambientes digitais mais eficientes. Neste cenário, desenvolver projetos de Arquitetura da Informação passou a ser um processo importante durante a construção de ambientes informacionais digitais, visando aprimorar a interação, bem como contemplar as necessidades dos usuários.

Adicionalmente, com a sua popularização, a Web foi evoluindo buscando organizar e representar com mais precisão os conteúdos deste ambiente. A Web Semântica é o principal movimento neste contexto, em que as tecnologias da Web Semântica buscaram aproximar os conteúdos criados pelos indivíduos aos agentes computacionais. 
A Web Semântica em um primeiro instante visava o desenvolvimento de tecnologias que estão focados na parte interna dos sistemas computacionais (backend), não tendo como objetivo direto as interfaces gráficas. Porém, vale destacar que indiretamente, a Web Semântica contribuiu com aplicações que melhoram a interação dos usuários com os ambientes informacionais digitais, pelo próprio impacto e influência que a parte interna dos sistemas computacionais tem sob as interfaces dos ambientes.

Neste contexto, tendo como prisma a teoria sistêmica da Arquitetura da Informação, que a divide em cinco sistemas (organização, rotulagem, navegação, busca e representação), verifica-se que a Web Semântica foi um elemento aprimorador da Arquitetura da Informação, pois ainda que não fosse objetivo original da Web Semântica, esta possibilitou com que a Arquitetura da Informação dos ambientes fossem mais personalizadas de acordo com o sentido dos conteúdos. Desta forma, os sistemas da Arquitetura da Informação podem ser otimizados, melhorando o projeto como um todo, por meio da aplicação das tecnologias da Web Semântica.

No sistema de organização, a Web Semântica pode contribuir na identificação do conteúdo, propiciando uma possibilidade de personalização da forma de apresentação do conteúdo para cada usuário. Assim, tendo claro para os agentes computacionais o que cada conteúdo significa, é possível aprimorar a organização do ambiente. As tecnologias da Web Semântica que estão principalmente vinculados a este sistema são: XML, RDF, RDF Schema, OWL, SPARQL e SWRL.

De forma semelhante, no sistema de rotulagem, as tecnologias da Web Semântica, XML, RDF. OWL, Microdados e RDFa, possibilitam criar rótulos que sejam significativos tanto para os usuários quanto para os computadores. Como consequência desse processo, mecanismos de buscas e agentes computacionais teriam facilidade de rastrear os conteúdos dos ambientes, ao mesmo tempo que são capazes de explorar e realizar inferências acerca dos dados disponibilizados.

No sistema de navegação, a Web Semântica pode contribuir indiretamente fornecendo meios que favoreçam a localização do usuário dentro de um ambiente. RDF, OWL e SPARQL são as tecnologias da Web Semântica que aprimoram tal sistema. 0 uso de aplicações como do Linked Data para esse processo, pode permitir uma forma distinta do usuário se encontrar e identificar a qual contexto 0 conteúdo do ambiente pertence.

Para o sistema de busca, identifica-se que as tecnologias da Web Semântica, OWL, RDF, RDF Schema, SPARQL e o SWRL, se encontram cada vez mais presentes, visando tornar o processo de busca mais semântico e inteligente. 0 uso de ontologias para auxiliar na identificação do significado do 
conteúdo vem aprimorando esse processo, além de iniciativas que visam tratar a busca por meio dos recursos, e não somente por palavras-chave entendidas como cadeias de caracteres.

0 último sistema, de representação, apresenta também uma forte influência das tecnologias da Web Semântica, em especial RDF, OWL, XML e SKOS. Tesauros, metadados, ontologias e vocabulários controlados construídos por meio dessas tecnologias tem favorecido o desenvolvimento de ambientes com um nível de semântica formal mais elevado, uma vez que tornam esses elementos que são essenciais nos ambientes, aptos a serem explorados por mecanismos computacionais, e assim, possibilitar a realização de inferências por eles.

A partir desta explanação de como os sistemas da Arquitetura da Informação estão associados às tecnologias e aos conceitos da Web Semântica, identifica-se que em todos os casos a Web Semântica está vinculada a Arquitetura da Informação, em que as suas tecnologias irão permitir, em suma, a inserção de uma semântica formal nos ambientes informacionais digitais.

Desta forma, a partir da inserção da Web Semântica nos sistemas da Arquitetura da Informação, estes ambientes são aprimorados, como pode ser visto em diversas aplicações que estão empregando os conceitos e as tecnologias da Web Semântica para isto. Aplicações como o Knowledge Graph que auxilia no processo de busca do Google ao trazer novos elementos aos usuários e uma nova organização dos ambientes com o uso das tecnologias da Web Semântica - e o Rich Snippets - que insere elementos enriquecidos nas páginas Web, seguindo os princípios do RDF, para aprimorarem 0 processo de busca - estão trazendo novas concepções a Arquitetura da Informação, a aprimorando e a tornando mais efetiva para cada usuário.

Em uma outra perspectiva, a Web Pragmática conduz a uma nova visão acerca da Web, trazendo a necessidade de contextualizar a informação, inserindo 0 usuário no centro deste processo. Como relata Decarli (2017), a Web Pragmática traz não somente o significado, mas como tal significado é empregado aos diversos grupos.

Neste sentido, Mota e Kobashi (2016, p. 13) discutem que: “[...] o contexto é, especificamente, a necessidade de informações, demandadas pela tarefa do indivíduo, sendo também influenciada por seu histórico profissional ou acadêmico." Diante deste cenário, verifica-se que o contexto da Web Pragmática está diretamente associado às especificidades dos usuários, em especial em como as suas necessidades de informação podem ser sanadas.

Desta forma, a implantação da Web Pragmática, naturalmente, depende do desenvolvimento e da aplicação de novas tecnologias, em que vale destacar, grande parte é oriunda das chamadas 
Tecnologias da Web Semântica, que devem ser refletidas com o uso e o desenvolvimento de novas tecnologias, utilizando por exemplo, princípios da Inteligência Artificial. No entanto, a partir do instante em que a Web Pragmática traz o foco no contexto do usuário e dos dados, somente o uso de tecnologias de fundo (backend), não são capazes de atingir o que tal Web está propondo. É necessário uma disrupção na integração entre tais tecnologias e na forma de interação e de desenvolvimento dos ambientes informacionais digitais, o qual é contemplado pela Arquitetura da Informação.

Assim, a Arquitetura da Informação passa a ter um papel central no processo da implantação da Web Pragmática, pois ela, cercada de campos de conhecimentos que utilizam de seu arcabouço teórico, é a responsável pela interface entre homem e máquina nos ambientes informacionais digitais, inclusive a Web. Neste contexto, compreende-se interface como a comunicação e a troca de informações entre duas partes distintas, não restringindo a Arquitetura da Informação a interfaces gráficas.

Quando enfocamos a Web Pragmática, a Arquitetura da Informação passa a ser o elemento chave em melhorar a comunicação entre o ambiente digital e o indivíduo contextual, ou seja, será por meio da Arquitetura da Informação, que se possibilitará aumentar o nível de compreensão do contexto em que um indivíduo se encontra (contextos pragmáticos). Tal processo, está contemplado principalmente nos novos constructos teóricos/aplicados que estão cingindo a Arquitetura da Informação, onde o enfoque está fundamentado em aprimorar a interação, possibilitar o encontro da informação e romper com as barreiras de virtual e real dentro destes ambientes informacionais digitais.

Na Encontrabilidade da Informação, Vechiato e Vidotti (2014) ao trazerem como contribuição que, este campo estuda a intersecção entre as funcionalidades do ambiente e as características dos sujeitos, expõe que as particularidades dos sujeitos, o que consequentemente está vinculado e depende do seu contexto (contextos individuais), devem ser elementos a serem considerados e essenciais no processo de encontrar uma informação (contexto comum). Assim, a Encontrabilidade da Informação traz as características dos indivíduos, bem como os seus contextos pragmáticos do ambiente digital.

Do mesmo modo, ligada à Arquitetura da Informação, encontra-se a Experiência do Usuário. Visar a satisfação do uso, requer inevitavelmente ter um outro prisma para os indivíduos, considerando elementos e condições que se vinculam ao contexto deste e do ambiente informacional digital (contexto pragmático). Desta forma, refletir e abordar técnicas de Experiência do Usuário ao pensar nos projetos de Arquitetura da Informação, apontam uma aproximação com a Web Pragmática, saindo de uma esfera sintática e semântica e chegando a um pragmatismo da Web. 
WEB, WEB SEMÂNTICA E WEB PRAGMÁTICA: um posicionamento da Arquitetura da Informação

Em uma outra perspectiva, a Arquitetura da Informação Pervasiva indica a configuração atual dos ambientes digitais baseada na Pervasividade, em que virtual e real estão entrelaçados (contextos pragmáticos). A Web passou a ser parte do cotidiano das pessoas, muitas vezes de forma tácita, sem que os indivíduos a percebam. Neste sentido, a Pervasividade reflete esse cenário, ao pensar na Arquitetura da Informação dos diversos ambientes informacionais digitais complexos e as ecologias informacionais inclusive da Web. A Web Pragmática está inserida neste âmbito, uma vez que a Web contextual deve ser parte dos diversos cenários ou contextos pragmáticos que as suportam.

Outros conceitos como Mobilidade, Responsividade, Usabilidade e Acessibilidade, também estão diretamente relacionados à Arquitetura da Informação trazendo contribuições à Web Pragmática, uma vez que são responsáveis por refletir: a Mobilidade e a Responsividade na criação e na adaptação dos ambientes aos novos dispositivos com características distintas dos computadores tradicionais, a Usabilidade e a Acessibilidade, focadas em aprimorar a capacidade de um ambiente ser utilizado e flexível para atender as necessidades e preferências dos usuários.

A partir dos campos de estudos apontados que cercam a Arquitetura da Informação como: Encontrabilidade da Informação, Pervasividade, Experiência de Usuário, Mobilidade, Responsividade, Usabilidade e Acessibilidade, identifica-se que a Arquitetura da Informação pode ser vista como a disciplina determinante que irá promover a Web Pragmática. Esta situação inverte a relação da Arquitetura da Informação com a Web Semântica, em que a primeira, quando olhada sob a perspectiva da teoria sistêmica seria somente aprimorada pela Web Semântica, e quando enfoca-se na Web Pragmática, esta não seria possível sem a Arquitetura da Informação, partindo dos seus novos constructos teóricos e campos de estudos apresentados.

0 cenário que reflete estes apontamentos é apresentado na figura 1, em que ao centro apresenta-se a Arquitetura da Informação, foco deste trabalho, e que está vinculada a todo o restante da figura. 0 círculo interno, em azul, representa a Web, em que os cinco sistemas da Arquitetura da Informação permitem que os ambientes informacionais digitais sejam estruturados. 0 segundo círculo, em verde, representa a Web Semântica, em que as diversas tecnologias que estão vinculadas a um determinado sistema da Al aprimoram a Arquitetura da Informação dos ambientes digitais. Por fim, o círculo externo, em vermelho, representa a Web Pragmática, em que os diversos campos de estudos vinculados a Arquitetura da Informação são capazes de permitir que a Web Pragmática possa ser materializada. 
Figura 1 - Relação da Arquitetura da Informação com a Web, a Web Semântica e a Web Pragmática

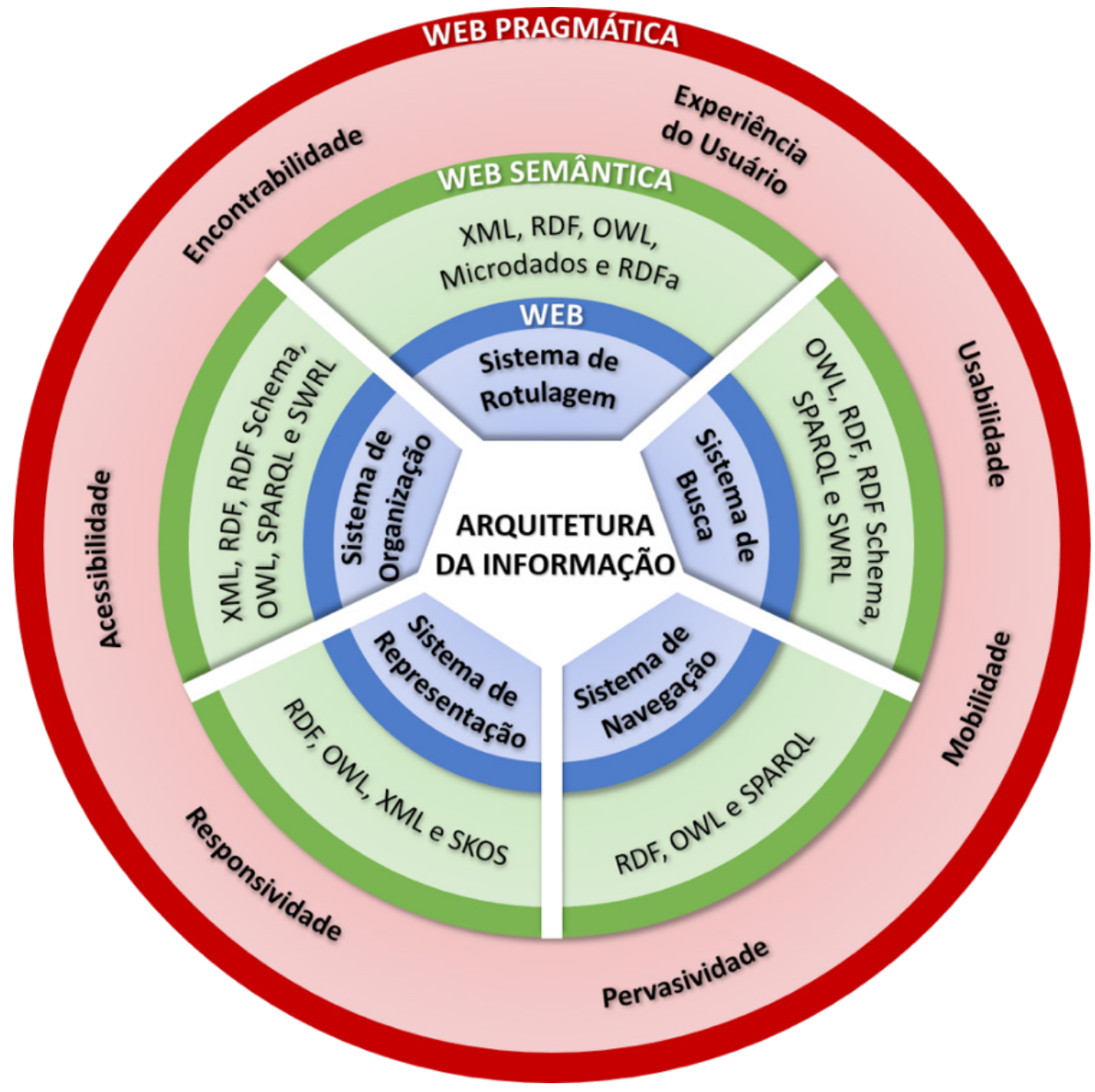

Fonte: Elaborado pelos autores.

A figura 1 sintetiza as questões relatadas anteriormente, demonstrando a relação entre Web, Web Semântica e Web Pragmática com a Arquitetura da Informação. Por meio da figura, é possível verificar que a Arquitetura da Informação tem um papel central na evolução da Web, em que a partir dos seus sistemas, a Arquitetura da Informação é aprimorada por meio das tecnologias da Web Semântica, que quando somada aos seus constructos epistemológicos possibilita a concretização da Web Pragmática.

\section{CONSIDERAÇÕES FINAIS}

0 projeto de ambientes informacionais digitais é uma tarefa essencial para permitir que os usuários consigam navegar e encontrar os recursos informacionais que melhor atendam às suas necessidades. Neste contexto, a Arquitetura da Informação buscou auxiliar nas construções destes 
ambientes ao fornecer teorias, técnicas e diretrizes que direcionam para 0 aprimoramento na interação dos usuários com estes ambientes informacionais digitais.

A Arquitetura da Informação com a sua teoria sistêmica auxilia significativamente neste processo, dividindo e indicando em cada sistema os elementos que devem ser considerados ao ser construído um projeto de Arquitetura da Informação de um ambiente informacional digital. Na Web inicial, ou Web sintática, a Arquitetura da Informação foi elemento importante para a construção de websites, trazendo reflexões fundamentais sobre como deveriam ser a organização, a navegação, a rotulagem, a busca e a representação da informação. A partir disso, pode-se considerar como uma Arquitetura da Informação Sintática, aquela com foco principal na sintaxe e na estrutura dos ambientes informacionais digitais a partir do detalhamento de elementos a serem contemplados nos sistemas da Arquitetura da Informação.

No presente trabalho, identificamos que com a evolução da Web, especialmente no que tange a Web Semântica, a Arquitetura da Informação passou a ser aprimorada com os conceitos e as tecnologias da Web Semântica, que forneciam elementos para explicitar o sentido que os recursos possuíam para os agentes computacionais. Neste sentido, a Arquitetura da Informação enquanto uma interface entre indivíduos e máquina, foi capaz de tirar proveito da Web Semântica para se aprimorar, permitindo 0 aperfeiçoamento dos seus sistemas. Neste cenário, reflete-se sob uma Arquitetura da Informação Semântica voltada ao significado e a interoperabilidade dos usuários humanos e não humanos com os ambientes informacionais digitais. Tal significado se baseia na estrutura destes ambientes, para 0 qual a Arquitetura da Informação se torna utilizadora das tecnologias da Web Semântica inserindo-as nos sistemas de organização, de navegação, de rotulagem, de busca e de representação da informação.

Aprofundando a relação entre a Web e a Arquitetura da Informação, o trabalho buscou verificar a relação entre a Web Pragmática e a Arquitetura da Informação. Neste sentido, quando se parte de novos construtos teóricos e epistemológicos da Arquitetura da Informação, em especial dos campos de estudos apresentados por estar relacionados a tal disciplina, como a Encontrabilidade da Informação, a Pervasividade, Experiência do Usuário, Usabilidade e Mobilidade, identificamos que a Web Pragmática pode ser materializada, por meio da Arquitetura da Informação.

Neste sentido, os contextos pragmáticos, contextos dos indivíduos e contextos comuns, parte central da Web Pragmática, só poderiam ser explorados por meio de uma interseção entre as tecnologias da Web Semântica e de outras ferramentas computacionais que deverão ser estudadas, por exemplo, a Inteligência Artificial, apontando na utilização das teorias e das práticas que os campos 
de estudos relacionados a Arquitetura da Informação supracitados são capazes de fornecer. Assim, aponta-se para uma Arquitetura da Informação Pragmática, a qual está orientada no significado baseado nos contextos pragmáticos gerados entre os usuários e os ambientes informacionais digitais, destacando que esta concepção e materialização fará possível 0 desenvolvimento da Web Pragmática.

Portanto, a relação entre a Arquitetura da Informação com a Web, no estágio da Web Semântica, está na primeira sendo uma utilizadora e sendo aprimorada pela segunda, enquanto a Web Pragmática a relação passa a ser da Arquitetura da Informação como um elemento fundamental que irá promover a materialização desta Web. Neste contexto, enquanto trabalho futuro cabe aprofundar como a Arquitetura da Informação, junto com seus campos relacionados, poderá fornecer técnicas e práticas para a implantação da Web Pragmática, se relacionando assim as tecnologias da Web Semântica e demais ferramentais computacionais necessários.

\section{REFERÊNCIAS}

BERNERS-LEE, T.; HENDLER, J.; LASSILA, 0. The semantic Web. Scientific American, v. 284, n. 5, p. 28-37, 2001.

CARRAR0, J.; DUARTE, Y. Experiência de Usuário (UX): cómo diseñar interfaces digitales amigables para las personas y rentables para las compañias. Buenos Aires: Autores de Argentina, 2015.

CONEGLIAN, C. S. et al. Tecnologias da Web Semântica na Arquitetura da Informação. Revista Interamericana de Bibliotecología. 2018. Em avaliação.

DECARLI, G. C. 0 Conhecimento Enciclopédico Colaborativo e suas Influências no

Desenvolvimento da Web Pragmática. 2017. Dissertação (Mestrado em Ciência da Informação), Universidade de Londrina, Londrina, 2017.

DIAS, G. A.; VIDOTTI, S. A. B. G. Arquitetura da Informação no Ambiente Digital: avaliando as relações com o Direito da Propriedade Intelectual. Informação \& Sociedade: Estudos, v. 22, n. 3, 2012

MOOR, A.; KEELER, M.; RICHMOND, G. Towards a pragmatic web, In: UTA, Priss et al. Conceptual Structures: Integration and Interfaces. Lecture Notes in Computer Science, v. 2393, p. 235-249, 2002. Disponível em: http://www.cspeirce.com/menu/library/aboutcsp/richmond/web.pdf . Acesso em 03 abr. 2018.

M00R, A. DE. Patterns for the Pragmatic Web. Conceptual Structures: Common Semantics for Sharing Knowledge. Anais... Lecture Notes in Computer Science. p.1-18. Springer, Berlin, Heidelberg. 2005. 
MONTEIRO, S. D. 0 ciberespaço e os mecanismos de busca: novas máquinas semióticas. Ciência da Informação, v. 35, n. 1, 2006.

MORVILLE, P. Ambient Findability. Sebastopol: O’Reilly, 2005.

MOTA, D. A. R.; KOBASHI, N. Y. Web semântica e web pragmática: discussão crítica sobre versionamento na web e limites conceituais. Tendências da Pesquisa Brasileira em Ciência da Informação, v. 9, n. 2, 2016.

MOTA, D. A. R. Representação e recuperação de informação em acervos digitais nos contextos da web semântica e web pragmática: um estudo crítico. 2015. Tese (Doutorado em Ciência da Informação) - Escola de Comunicações e Artes, Universidade de São Paulo, São Paulo, 2015. Disponível em: http://www.teses.usp.br/teses/disponiveis/27/27151/tde-27012016-135403/. Acesso em: 03 abr. 2018.

NIELSEN, J. 10 Usability Heuristics for User Interface Design. 1995. Disponível em:https://www. nngroup.com/articles/ten-usability-heuristics/. Acesso em: 03 abr. 2018.

OLIVEIRA, H. P.; VIDOTTI, S. A. B. G. V. Al digital: conexões interdisciplinares dentro da abordagem sistêmica. In: CAVALCANTE, L. E.; PINTO, V. B.; VIDOTTI, S. A. B. G. V. (Eds.). Ciência da informação e contemporaneidade: tessituras e olhares. Fortaleza: Edições UFC, 2012. p. 184-202.

OLIVEIRA, H. P. C. Arquitetura da Informação Pervasiva: Contribuições Conceituais. 2013. 203 f. Tese (Doutorado em Ciência da Informação) - Faculdade de Filosofia e Ciências, Universidade Estadual Paulista, Marília, 2013.

PINTO, J. Pragmática. In: MUSSALIN, F.; BENTES, A. C. (Orgs.). Introdução à linguística: domínios e fronteiras. São Paulo: Cortez, 2006.

RICHMOND, GARY. Interoperability as Desideratum, Problem, and Process. Conceptual Structures Tool Interoperability Workshop. 2006.

RESMINI, A.; ROSATI, L. Pervasive information architecture: designing cross-channel user experiences. Burlington: Elsevier, 2011b.

ROSENFELD, L.; MORVILLE, P. Information architecture for the World Wide Web. 1st ed ed. Cambridge ; Sebastopol, CA: O’Reilly, 1998.

ROSENFELD, L.; MORVILLE, P.; ARANGO, J. Information architecture: for the web and beyond. Fourth edition ed. Sebastopol, CA: O’Reilly Media, Inc, 2015.

SANTAREM SEGUNDO, J. E.; CONEGLIAN, C. S. Web semântica e ontologias: um estudo sobre construção de axiomas e uso de inferências. Informação \& Informação, v. 21, n. 2, p. 217-244, 2016. Disponível em: http://www.uel.br/revistas/uel/index.php/informacao/article/view/26417. Acesso em: 03 abr. 2018. 
OUZA, R. R.; ALVARENGA, L. A Web Semântica e suas contribuições para a ciência da informação. Ciência da Informação, Brasília, v. 33, n. 1, p. 132-141, 2004.

VECHIATO, F. L.; VIDOTTI, S. A. B. G. Encontrabilidade da informação. São Paulo: Cultura Acadêmica, 2014b. (Coleção PROPG Digital-UNESP). ISBN 9788579835865. Disponível em: http:// hdl.handle.net/11449/126218. Acesso em: 02 nov. 2017.

WYLLYS, R. E. Information Architecture. 2000. Disponível em: https://www.ischool.utexas. edu/ |38613dw/readings/InfoArchitecture.html. Acesso em: 03 abr. 2018. 